\title{
The Effect of Endurance-Type Exercise Training on Growth Mediators and Inflammatory Cytokines in Pre-Pubertal and Early Pubertal Males
}

\author{
TIMOTHY P. SCHEETT, DAN NEMET, JAMES STOPPANI, CARL M. MARESH, \\ ROBERT NEWCOMB, AND DAN M. COOPER
}

Center for the Study of Health Effects of Exercise in Children, University of California, Irvine, College of Medicine, Orange, California, U.S.A. [T.P.S., D.N., R.N., D.M.C.]; Human Performance Laboratory, Department of Kinesiology, University of Connecticut, Storrs, Connecticut, U.S.A. [T.P.S., J.S., C.M.M.]

\begin{abstract}
Recent studies demonstrate an unexpected reduction in circulating levels of IGF-I after 5 wk of endurance-type exercise training in adolescent boys and girls and prepubertal girls. We hypothesized that the reduction in IGF-I would be accompanied by a training-associated stimulation of proinflammatory cytokines IL-1 $\beta$, IL-6, or tumor necrosis factor- $\alpha$ (TNF- $\alpha$ ), each of which can inhibit the $\mathrm{GH} \rightarrow \mathrm{IGF}-\mathrm{I}$ axis. Healthy boys (age range 9-11 y old, mean Tanner 1.7) volunteered for the study and were randomized to control $(n=14)$ and training groups $(n=12)$ for $5 \mathrm{wk}$. After the intervention, significant increase in fitness was observed in the training group but not control group. Although IGF-I was correlated at baseline to peak oxygen consumption in all subjects, there was a significant decrease in IGF-I and IGF binding protein-3 in the training subjects $(-12.8 \pm 7.3 \%$ and $-17.5 \pm 7 \%$, respectively, $p<0.05$ ). In contrast, IGF binding

protein-2, known to inhibit anabolic effects of IGF-I, increased in the training subjects $(27.8 \pm 11 \%, p<0.02)$ as did IL-1 $\beta$ and TNF- $\alpha(51.5 \pm 30.22 \%, p<0.02$, and $44.5 \pm 23.2 \%, p<0.02$, respectively). Finally, we also found that GHBP was inversely correlated with fitness, suggesting altered GH function in moresedentary boys. Thus, these data support the hypothesis that a sustained increase in physical activity can stimulate proinflammatory cytokines, which may contribute to suppression of the $\mathrm{GH} \rightarrow$ IGF-I axis. Physical activity can influence growth and development through its influence on anabolic and catabolic mediators. (Pediatr Res 52: 491-497, 2002)
TNF- $\alpha$, tumor necrosis factor- $\alpha$
IGFBP, IGF binding protein

\section{Unauthorized Use}

The $\mathrm{GH} \rightarrow \mathrm{IGF}-\mathrm{I}$ axis is a system of growth mediators, receptors, and binding proteins that control somatic and tissue growth in many species (1). Exercise training is linked to anabolic function through this axis, as previous cross-sectional studies from this and other groups have demonstrated that $\mathrm{GH}$ pulsatility and circulating IGF-I are higher in fitter adolescents and adults (2-5). In contrast, we have consistently demonstrated a decrease in circulating elements of the GH-IGF-I axis in postpubertal males and females and in prepubertal girls in response to aerobic exercise $(6,7)$. This was surprising for two reasons: first, because the training regimen led to significant increases in muscle mass and fitness without weight loss; and

Received November 19, 2001; accepted April 12, 2002

Correspondence: Dan M. Cooper, M.D., Professor of Pediatrics-UCI College of Medicine, Clinical Research Center, Building 25, ZOT 4094-03, 101 The City Drive, Orange, CA 92868, U.S.A.; e-mail: dcooper@uci.edu

Supported by grants MO1-RR00827 and HD 23969 from the National Institutes of Health. D.N. is a Postdoctoral Research Fellow of the Joseph W. Drown Foundation.

DOI: 10.1203/01.PDR.0000030876.20888.BF

secondly, because IGF-I is known to be correlated with fitness in adults and adolescents, indicating a training-associated enhancement of anabolic activity (3-5).

Although the exact mechanism for this suppression of the $\mathrm{GH} \rightarrow \mathrm{IGF}-\mathrm{I}$ axis is unknown, one possibility may involve the exercise-induced increase in the proinflammatory cytokines IL-1 $\beta$, IL-6, and/or TNF- $\alpha$. The inflammatory cytokines are a group of low-molecular-weight polypeptides involved in cellto-cell communication, including immune function and inflammatory responses after acute and chronic stimuli. Several studies have reported that exercise acutely resulted in an elevation of serum cytokine concentrations, namely IL- $1 \beta$, IL-6, and TNF- $\alpha$ (8). These inflammatory cytokines may decrease circulating IGF-I levels through a number of ways and may attenuate the IGF-I bioactivity via increasing the inhibitory IGFBP. A recent investigation by our group reported that an acute $90-\mathrm{min}$ exercise bout resulted in significant increases in IL-6, TNF- $\alpha$, and IGFBP-1, with a concomitant decrease in IGF-I in prepubescent boys (9).
\end{abstract}


Therefore, the purpose of this current study was to investigate the interaction between serum growth factors and the inflammatory cytokines. We hypothesized that a 5-wk aerobictype exercise intervention would also lead to an attenuation of $\mathrm{GH} \rightarrow$ IGF-I activity in pre-pubertal and early pubertal boys. We additionally hypothesized that a possible mechanism for the suppression in IGF-I is an exercise-associated stimulation of proinflammatory cytokines.

\section{METHODS}

Sample population. Twenty-nine healthy pre-pubertal and early pubertal boys originally volunteered to participate in this study. The subjects were all students in a local summer school with class hours from 0830 to $1130 \mathrm{~h}$. The ethnic configuration of the group was 59\% Caucasian, 31\% Asian, 7\% East Indian, and $3 \%$ Hispanic. No attempt was made to recruit subjects who participated in competitive extramural athletic programs. The study was designed to examine pre-pubertal and early pubertal males with an age range of $8-11$ y (mean $10.0 \pm 0.3 \mathrm{y}$ ). Measurements of height and weight were made using standard techniques. Body composition was assessed using a pediatric specific two-site (tricep and calf) skinfold equation (10). All preparticipation and postparticipation skinfold thicknesses were measured by the same technician using a Lange skinfold caliper.

A preparticipation physical and history was performed by a staff pediatrician to ensure that all subjects were healthy and capable of participating in a training program. Assessment of pubertal status was performed by examination in all of the subjects. Eight of the subjects were found to be at Tanner level I, 18 at Tanner level II, and three between Tanner level II and III. To focus the study on early puberty, the data from/these three subjects were not included in the analysis.

The participants were randomized to a control $(n=14)$ or training group $(n=12)$. Control subjects enrolled in four 45-min "sit-down" courses. Training group subjects participated in 90 min of aerobic-type activity interspersed throughout the $3 \mathrm{~h}$ each day. The subjects participated in the program $5 \mathrm{~d}$ a week for $5 \mathrm{wk}$. The aerobic-type training consisted of age-appropriate and sport-specific drills and games as well as running, jumping, aerobic dance, and competitive sports (about $50 \%$ team sports and $50 \%$ running games, e.g. flag football, rugby, soccer, etc.). The aerobic activity sessions were separated by periodic "sit-down" classroom instruction time. The intervention was designed to mimic the type and intensity of exercise that elementary school boys normally perform. These activities were varied in duration and intensity throughout the week, and were designed primarily as games to encourage enthusiasm and participation of the subjects.

No attempt was made to influence extracurricular levels of physical activity in either the control or trained groups, but participants were asked not to change their activity patterns from those before the study. The study was approved by the institutional human subject review board. Informed assent was obtained from the subjects and informed consent from their parents or guardians.

Measurements of fitness. We assessed peak oxygen uptake ( $\dot{\mathrm{O}}_{2}$ peak) before and after the training intervention using a ramp-type progressive exercise test on a cycle ergometer in which the subject exercised to the limit of his tolerance. Gas exchange was measured breath-by-breath (11) and the $\dot{\mathrm{V}}_{2}$ peak was determined as previously described for children and adolescents (12).

Blood sampling protocols. Subjects were admitted to the General Clinical Research Center at the University of California, Irvine, Medical Center. An early morning, fasting blood sample was collected from a forearm vein for measurements of circulating IGF-I, IGFBP-1-3, GH binding protein (GHBP), IL-1 $\beta$, TNF- $\alpha$, IL-6, IL-1 receptor antagonist (IL-1ra), and cortisol. Blood samples were collected the week before, and within 2-3 d after the completion of the training intervention and serum samples were stored at $-70^{\circ} \mathrm{c}$. None of the subjects trained during the day preceding the blood sampling. All preintervention and postintervention specimens were analyzed in the same batch by technicians who were blinded to the group and order of the samples.

IGF-I. IGF was extracted from IGFBP using the acidethanol extraction method (13). Serum IGF-I concentrations were determined by a two-site immunoradiometric assay (IRMA) using the DSL-5600 Active kit (Diagnostic System Laboratories, Webster, TX, U.S.A.). IGF-I interassay coefficient of variation $(\mathrm{CV})$ was $3.7-8.2 \%$ and intra-assay $\mathrm{CV}$ was $1.5-3.4 \%$. Assay sensitivity was $0.8 \mathrm{ng} / \mathrm{mL}$.

IGFBPS 1-3. IGFBP-1 and -3 were measured by coated-tube IRMA. IGFBP-2 was measured by RIA. Serum IGFBP-1-3 were measured using commercially available kits (Diagnostic System Laboratories Inc.). For IGFBP-1, interassay CV was $1.7-6.7 \%$ and intra-assay CV was $2.1-4.2 \%$. Assay sensitivity was $0.11 \mathrm{ng} / \mathrm{mL}$. For IGFBP-2, interassay CV was $6.4 \%$ and intra-assay CV was 6.5\%. Assay sensitivity was $0.5 \mathrm{ng} / \mathrm{mL}$. For IGFBP-3, interassay $\mathrm{CV}$ was $0.6-1.9 \%$ and intra-assay $\mathrm{CV}$ was $1.8-3.9 \%$. Assay sensitivity was $0.5 \mathrm{ng} / \mathrm{mL}$.

$\boldsymbol{G H B P}$. GHBP was measured using the ligand-mediated immunofunctional assay (14). Interassay $\mathrm{CV}$ was $9.7-12.9 \%$ and intra-assay $\mathrm{CV}$ was $6.3-8.9 \%$. Assay sensitivity was $7.8 \mathrm{pmol} / \mathrm{L}$. Cortisol. Serum cortisol levels were determined by a commercial RIA (Diagnostic Products, Los Angeles, CA, U.S.A.). The intra- and interassay CV for this assay were $3.2 \%$ and $6.8 \%$, respectively.

Inflammatory cytokines. Serum IL- $1 \beta$, TNF- $\alpha$, IL- 6 , and IL-1ra were measured via ELISA from R \& D Systems (Minneapolis, MN, U.S.A.). For IL-1 $\beta$, interassay CV was 5.3$9.0 \%$, intra-assay $\mathrm{CV}$ was $1.6-4.0 \%$, and assay sensitivity was $0.059 \mathrm{pg} / \mathrm{mL}$. For TNF- $\alpha$, interassay $\mathrm{CV}$ was $7.8-10.4 \%$, intra-assay CV was $5.6-6.1 \%$, and assay sensitivity was 0.180 $\mathrm{pg} / \mathrm{mL}$. For IL-6, interassay CV was 7.1-29.5\%, intra-assay CV was $3.8-11.1 \%$, and assay sensitivity was $0.094 \mathrm{pg} / \mathrm{mL}$. For IL-1 ra, interassay CV was $4.4-6.7 \%$, intraassay CV was $3.1-6.2 \%$, and assay sensitivity was $21.9 \mathrm{pg} / \mathrm{mL}$.

Statistical analysis. Unpaired $t$ tests were used to determine differences in circulating components of the GH-IGF-I axis, cytokines, and demographic data between control and training group subjects before the training intervention. Two-way repeated measures ANOVA was used to compare the effect of the intervention on circulating components of the GH-IGF-I axis and cytokines, with time serving as the within-group 
factor and training as the between-group factor. When ANOVA was found to be significant, intergroup comparisons were made using modified $t$ tests by the method of Duncan. Pearson correlation was used for the cross-sectional studies relating the circulating components of the GH-IGF-I axis, cytokines, and fitness data. Statistical significance was set at $\alpha$ $=0.05$ level. Data are presented as mean $\pm \mathrm{SE}$.

\section{RESULTS}

\section{Effects of Training on Body Size and Fitness}

Subject characteristics are presented in Table 1. No significant differences were found between the trained and control groups. Before the intervention, $\dot{\mathrm{V}}_{2}$ peak $/ \mathrm{kg}$ (control and training) was negatively correlated to body mass index (BMI) percentile $(r=-0.65, p<0.0005)$. The training protocol resulted in a significant increase in $\dot{\mathrm{V}}_{\mathrm{O}_{2}}$ peak $(44.8 \pm 1.6$ to $50.5 \pm 2.1 \mathrm{~mL} / \mathrm{kg} / \mathrm{min}, p=0.002)$ in the trained group while the control group had a nonsignificant decrease in $\dot{\mathrm{V}}_{2}$ peak $(44.8 \pm 2.4$ to $43.0 \pm 2.2 \mathrm{~mL} / \mathrm{kg} / \mathrm{min}$, NS), resulting in a significant difference between the groups $(12.9 \pm 3.7 \%,-3.51$ $\pm 2.9 \%, p=0.0009$ ). No changes were observed in body weight or fat percentage after the intervention.

\section{Circulating Components of the GH-IGF-I Axis}

Cross-sectional data. The strongest correlations between either body composition or fitness and elements of the GH $\rightarrow$ IGF-I axis were found for GHBP. GHBP was positively correlated with body weight $(r=0.74, p<0.0005)$ and BMI percentile $(r=0.73, p<$ 0.0005 , Fig. 1) and was negatively correlated with the normalized peak $\dot{\mathrm{V}}_{2} \cdot / \mathrm{kg}(r=-0.53, p<0.005)$. IGF-I was significantly correlated with peak $\dot{\mathrm{V}}_{2}(r=0.49, p<0.013)$. Finally, IL-1ra was found to be negatively correlated with the normalized peak $\dot{\mathrm{V}}_{\mathrm{O}_{2}} \cdot \mathrm{kg}(r=-0.51, p<0.009)$.

Effects of exercise training. The effects of the 5-wk aerobictype exercise training protocol on circulating components of the GH-IGF-I axis and cytokines are summarized in Tables 2 and 3 , and Figures 2-4. Before the training intervention, we observed significant differences between the exercise and control groups in GHBP, IL-6, and TNF- $\alpha$. Training resulted in a significant decrease in IGF-I and IGFBP-3 while eliciting a significant increase in IGFBP-2. Exercise training had no effect on IGFBP-1.

Training also led to a significant increase in the proinflammatory cytokines IL- $1 \beta$ and TNF- $\alpha$. IL- 6 decreased signifi-

Table 1. Subject characteristics

\begin{tabular}{lcc}
\hline & $\begin{array}{c}\text { Control } \\
(n=14)\end{array}$ & $\begin{array}{c}\text { Trained } \\
(n=12)\end{array}$ \\
\hline Age $(\mathrm{y})$ & $10.04 \pm 0.34$ & $9.95 \pm 0.42$ \\
Tanner stage $(n)$ & 5 & 3 \\
1 & 9 & 9 \\
2 & $140.7 \pm 1.9$ & $140.9 \pm 2.8$ \\
Height $(\mathrm{cm})$ & $36.83 \pm 2.1$ & $33.75 \pm 2.7$ \\
Weight $(\mathrm{kg})$ & $18.44 \pm 0.8$ & $16.71 \pm 0.7$ \\
BMI $\left(\mathrm{kg} / \mathrm{m}^{2}\right)$ & $23.8 \pm 2.5$ & $22.4 \pm 2.1$ \\
Percent fat (skin folds) & & \\
\hline
\end{tabular}

Results are shown as mean \pm SE. No statistically significant differences were noted between the groups in any of these measures. BMI, body mass index.

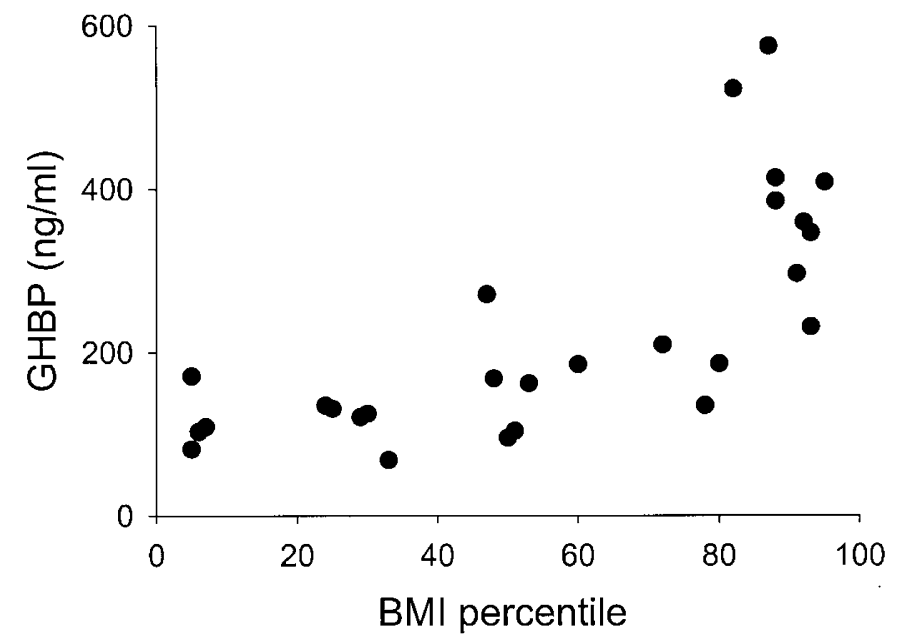

Figure 1. Correlation between GHBP and body composition (expressed as BMI percentile). A positive correlation $(r=0.73 p<0.0005)$ was found. The data also suggest a BMI percentile threshold ( $\sim 80$ th percentile) above which GHBP increases dramatically, suggestive of GH suppression.

eantly in the control group, with no significant change in the training group subjects, and there was a significant betweengroup difference in the IL-6 response $(p<0.04)$.

The decrease in IGFBP-3 $(\Delta \mathrm{BP} 3)$ was negatively correlated with the increase in TNF- $\alpha(r=-0.562, p=0.003)$ and with the change in IL-6 $(r=-0.41, p=0.042)$. We also found a positive correlation between the increase in fitness and the increase in TNF- $\alpha(r=0.54, p=0.002)$.

\section{V/II W DISCUSSION}

The present study demonstrates that a 5-wk aerobic-type exercise protocol leads to a significant increase in peak $\dot{\mathrm{V}}_{2}$ in healthy pre-pubertal and early pubertal boys. Previous studies from this and other laboratories suggest that about $50 \%$ of the increase in the peak $\dot{\mathrm{V}}_{2}$ from this type of training program is due to an increase in muscle mass (15). Despite the apparent anabolic adaptation in the training subjects, the training program was not accompanied by measurable increases in IGF-I, as might be expected from previous cross-sectional studies (3). In fact, training in this group of pre-pubertal and early pubertal boys led to significant decreases in the growth mediators IGF-I and IGFBP-3 (Figs. 2 and 3). IGFBP-3 is responsible for $>90 \%$ of binding of IGF-I, and some investigators suggest that IGFBP-3 may activate anabolic bioactivity of IGF-I (16). The IGF-I results presented here are consistent with previous results from our group using similar protocols in prepubertal girls (5) and adolescent boys (6) and girls (7) (Fig. 2).

A potential confounding variable in the interpretation of these results is the duration of the reduction of IGF-I observed in response to exercise. Acute exercise leads to a brief increase in IGF-I, but, if the exercise is sufficiently intense, is followed by a reduction $(17,18)$. There are no studies that have examined the duration of the exercise-associated reduction in circulating IGF-I, but recent observations from Nindl et al. (19) indicate that IGF-I returns to baseline levels at least overnight after a heavy bout of exercise. 
Table 2. The effect of $5 \mathrm{wk}$ endurance-type exercise training on circulating components of the GH-IGF-I axis and cortisol in pre-and early pubertal males

\begin{tabular}{|c|c|c|c|c|}
\hline & \multicolumn{2}{|c|}{ Control $(n=14)$} & \multicolumn{2}{|c|}{ Trained $(n=12)$} \\
\hline & Pre pubertal & Post pubertal & Pre pubertal & Post pubertal \\
\hline IGF-I (ng/mL)† & $180.4 \pm 15.2$ & $166.8 \pm 17.1$ & $202.75 \pm 20.2$ & $173.4 \pm 21.4 *$ \\
\hline IGFBP-2 $(\mathrm{ng} / \mathrm{mL}) \dagger$ & $457.3 \pm 31.9$ & $469.5 \pm 36.5$ & $351.4 \pm 44.5$ & $429.0 \pm 54.2^{*}$ \\
\hline IGFBP-3 $(\mathrm{ng} / \mathrm{mL}) \dagger$ & $43.4 \pm 1.8$ & $43.0 \pm 1.6$ & $42.9 \pm 1.9$ & $34.8 \pm 3.3^{*}$ \\
\hline GHBP $(\mathrm{pmol} / \mathrm{L})$ & $251.3 \pm 38.5$ & $241.4 \pm 38.9$ & $153.2 \pm 25.6$ & $151.0 \pm 22.4$ \\
\hline Cortisol $(\mathrm{nmol} / \mathrm{L}) \dagger$ & $264.6 \pm 38.5$ & $193.0 \pm 23.6^{*}$ & $265.4 \pm 30.5$ & $271.5 \pm 32.7$ \\
\hline
\end{tabular}

Results are shown as mean \pm SE. $* p<0.05$ within group; $\uparrow p<0.05$, between groups.

Table 3. The effect of 5 wk endurance-type exercise training on inflammatory cytokines in pre- and early pubertal males

\begin{tabular}{|c|c|c|c|c|}
\hline & \multicolumn{2}{|c|}{ Controls $(n=14)$} & \multicolumn{2}{|c|}{ Trained $(n=12)$} \\
\hline & Pre pubertal & Post pubertal & Pre pubertal & Post pubertal \\
\hline IL-1 $\beta(\mathrm{pg} / \mathrm{mL}) \dagger$ & $0.96 \pm 0.43$ & $0.57 \pm 0.20$ & $0.76 \pm 0.24$ & $0.98 \pm 0.27 *$ \\
\hline IL-6 $(\mathrm{pg} / \mathrm{mL}) \dagger$ & $1.60 \pm 0.16$ & $1.08 \pm 0.16^{*}$ & $0.6 \pm 0.06$ & $0.63 \pm 0.05$ \\
\hline IL-1ra (pg/mL) & $247.2 \pm 42.6$ & $176.6 \pm 17.4$ & $261.96 \pm 19.69$ & $261.45 \pm 19.21$ \\
\hline
\end{tabular}

Results are shown as mean \pm SE. ${ }^{*} p<0.05$, within groups; $\dagger p<0.05$ between groups.

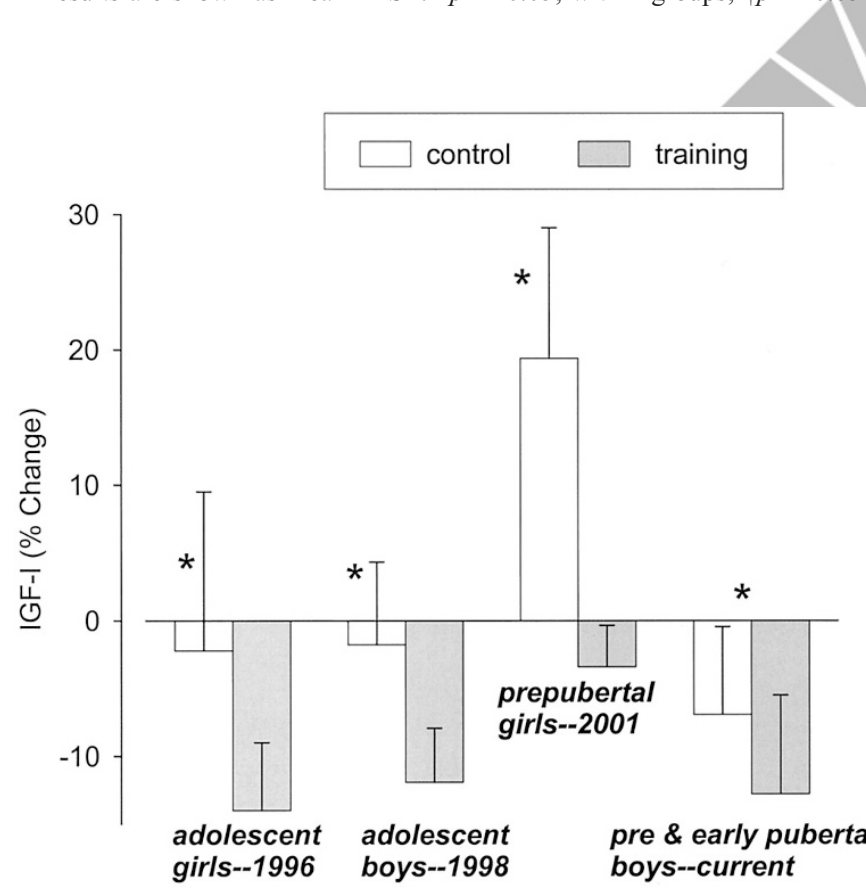

Figure 2. Effect of $5 \mathrm{wk}$ of endurance-type exercise training on circulating levels of IGF-I in healthy children and adolescents. Previously published data from similar experiments conducted by this research group (see text) are redrawn here from adolescent females, adolescent males, and prepubertal girls. In adolescents, there was a significant reduction in IGF-I. In prepubertal girls, an increase in IGF-I in the control subjects was attenuated by participation in the exercise training program. In the present study in pre-pubertal and early pubertal boys, there was a small but significant $(* p<0.05)$ decrease in IGF-I observed only in the training subjects. In all cases, the initial hypothesis that exercise training would lead to an increase in IGF-I levels was not supported.

In addition to the reduction in IGF-I, we also observed significant elevation in the proinflammatory cytokines IL-1 $\beta$ and TNF- $\alpha$ in the trained but not control subjects. IGFBP-2 [one of the IGF binding proteins believed to inhibit IGF-I bioactivity (20)] was also elevated after training (Fig. 3). Interestingly, IL-6 decreased in the control subjects as did

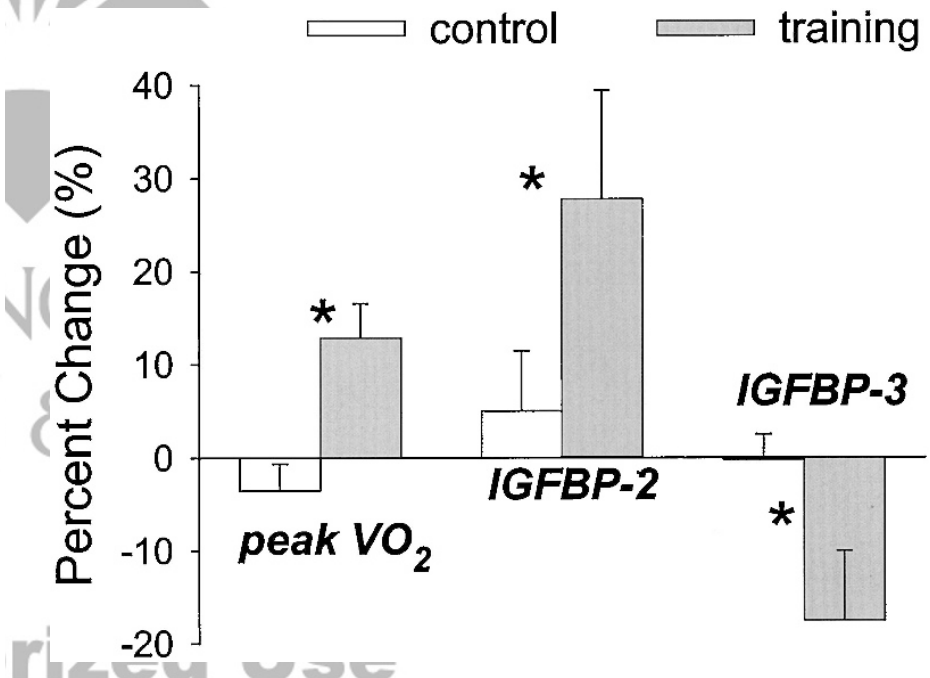

Figure 3. Effect of 5 wk of aerobic-type exercise protocol on $\dot{\mathrm{V}}_{2}$ peak, IGFBP-2, and IGFBP-3. Data are expressed as the mean \pm SE percentage change of each variable. $\dot{\mathrm{V}}_{2}$ peak and IGFBP-2 were significantly increased whereas IGFBP-3 was significantly decreased after the 5-wk exercise protocol $(* p<0.05$, between groups).

cortisol, but these decreases were not observed in the training group. Elevated cortisol and inflammatory cytokines reflect both psychosocial and physical stress (i.e. activation of the hypothalamic-pituitary axis). Thus, it is possible that stress was reduced in control subjects over the 5-wk period, but that participation in the exercise program inhibited the conditions of the summer school that were limiting stress. Finally, it is also possible that seasonal variations in cortisol levels were responsible for the decrease observed in the control subjects. A summer seasonal reduction in cortisol has been observed in adults (21). Perhaps the training program prevented a seasonalrelated cortisol decrease in the exercising group.

Our data also imply an endocrine response in the healthy training group children that is more classically consistent with 


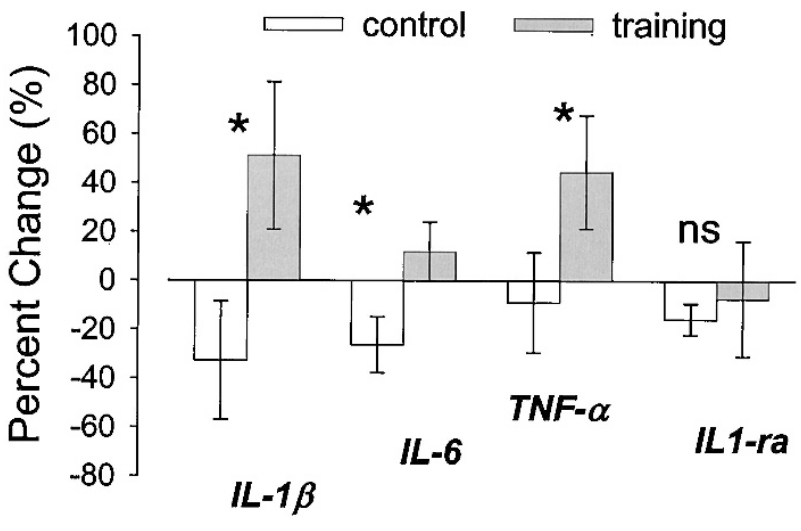

Figure 4. Effect of $5 \mathrm{wk}$ of aerobic-type exercise protocol on serum inflammatory cytokines IL-1 $\beta$, IL-6, TNF- $\alpha$, and IL-1ra. Data are expressed as the mean \pm SE percentage change of each variable. There were significant elevations in IL- $1 \beta$ and TNF- $\alpha$. IL- 6 increased in the exercise group but not significantly so; however, compared with the control group this change was statistically significant. IL-1ra did not change significantly $\left({ }^{*} p<0.05\right.$ between groups).

a catabolic rather than anabolic environment. Indeed, subjects with the greatest increases in TNF- $\alpha$ and IL- 6 over the training period tended to have the largest reductions in IGFBP-3. Moreover, the subjects who improved the most (i.e. with greatest increase in $\mathrm{Vo}_{2} \mathrm{max} / \mathrm{kg}$ ) were the ones with greatest increase in the proinflammatory cytokine TNF- $\alpha$.

The data support the notion of an IGF-I paradox raised previously by our group. IGF-I decreased in the training subjects after $5 \mathrm{wk}$ without loss of body weight or alterations in body composition, and despite increases in cardiorespiratory responses to exercise. Although we did not report intervention effects on nutrient intake, which clearly could influence levels of circulating IGF-I (22), the lack of change in either/body weight, BMI, or percentage body fat are not consistent with a nutritional cause for the reduction in circulating IGF-I. Our data do suggest, however, that the mechanism for the reduction in IGF-I and IGFBP-3 in the pre-pubertal and early pubertal boys might be, in part, related to a training-associated increase in basal levels of certain proinflammatory cytokines.

Divergent IGF-I responses to exercise have been previously observed. As noted, cross-sectional data indicate that circulating IGF-I is correlated with muscle mass and cardiorespiratory indexes of fitness. Moreover, a number of recent studies have shown prospectively that IGF-I increases with training (23, 24). But, as noted above, Smith et al. (22) studied a group of healthy young adult males for $10 \mathrm{~d}$ and found that increased physical activity exacerbated the well-described reduction in IGF-I that had been known to accompany caloric restriction. In adolescents, reduced IGF-I associated with training has been observed in high school wrestlers and in highly trained female gymnasts $(25,26)$. But in these previous studies, the exercise training program was accompanied by loss in body mass, providing clear evidence for a true catabolic state. By contrast, in the present study, as well as in our previous observations from this series in prepubertal girls and adolescents, no weight loss was observed over the duration of the training period. These data suggest that the initial reduction in circulating IGF-I in response to training is related specifically to exercise and not only to alterations in overall energy balance.
What is it about exercise that might lead to reductions in circulating levels of IGF-I ? One hypothesis is that single bouts of exercise in children could, like in adults $(27,28)$, stimulate proinflammatory cytokines known to directly inhibit anabolic activity of the GH $\rightarrow$ IGF-1 axis. The cumulative effect of these individual exercise perturbations would be to lower basal levels of IGF-I. As an extreme example of this paradigm, in children with systemic inflammatory diseases, chronically elevated IL-6 leads to reduced basal IGF-I and impaired somatic growth (29-31). In support of this hypothesis is recent evidence from our group demonstrating increases in IL-6, TNF- $\alpha$, and IL-1ra after a standard soccer practice in prepubertal children (9).

The data from the current study also corroborate the inflammatory cytokine hypothesis. However, in the present study, we did not measure the acute response to single exercise bouts but, rather, the cumulative effect of an exercise training program. We found significant increases in resting levels of IL- $1 \beta$ and TNF- $\alpha$ after the 5-wk training period only in the training-group subjects. Although the cytokine response to acute exercise is being studied extensively, far less is known about the longerterm effects of training on basal levels of these mediators. Smith (32) has suggested that, in adults, sustained circulating levels of proinflammatory cytokines like TNF- $\alpha$ may be detectable in the overuse syndrome found in individuals who train excessively. We speculate that any training program in which there is a substantial increase in energy expenditure due to physical activity leads initially to an increase in circulating levels of proinflammatory cytokines.

Further, if the training adaptation is successful, the proinflammatory cytokines fall, and with that decrease, the suppression of IGF-I diminishes. A rebound in GH $\rightarrow$ IGF-I axis may occur and, eventually, IGF-I exceeds the pretraining levels. In this model, fitter children, i.e. those who more frequently participate in vigorous physical activity, will have less evidence of activation of proinflammatory cytokines than do less-fit children. Consistent with this speculation is the observation that IL-1 ra was inversely correlated with peak $\dot{\mathrm{V}}_{\mathrm{O}_{2}} / \mathrm{kg}$ (in all subjects before the intervention). Although IL-1ra serves, physiologically, an antiinflammatory role, IL-1ra is stimulated by the proinflammatory cytokine IL-6. Consequently, IL-1ra is a marker for activation of the inflammatory cascade. Perhaps the inflammatory response to individual bouts of exercise diminishes with training, IL-6 stimulation of IL-1ra is attenuated as well, and fitter children have lower steady-state levels of IL-1ra.

Our study raises new questions about the role of inflammatory cytokines in healthy children. The role of these cytokines in pathologic states ranging from common colds to substantial trauma is well documented (33); but the idea that fluctuations of these mediators occur in response to common activities like increases in physical activity in healthy children is novel. Moreover, most studies would suggest that the proinflammatory cytokines are catabolic for those tissues, like muscle, involved in the training responses (34).

Ironically, the reduction in IGF-I and increase in proinflammatory cytokines occurred despite an increase in peak $\dot{\mathrm{V}}_{2}$, reflecting, most likely, increases in muscle mass. Clearly, some compensatory mechanisms modulated these responses so that local muscle growth could occur despite the systemic appearance of 
GH suppression. These mechanisms possibly include some that we did measure, for example, the training-associated increase in IL-1ra. This agent is stimulated by the inflammatory cytokines and acts to block their biologic activity at the receptor level. In this study, we did not measure free and bound IGF-I, but a number of investigators have suggested that processes like IGFBP-3 proteolysis, known to increase with acute exercise (35), could preserve unbound, more biologically available, IGF-I and, in this manner, mitigate the effects of an overall reduction in circulating IGF-I. Finally, there is evidence that even the proinflammatory cytokines might, under the right conditions, act to promote muscle growth and angiogenesis, processes necessary to the adaptive response to exercise training (36-38).

A number of insights were gained from the analysis of the relationship between initial fitness and body composition and growth factors and cytokine data collected from all subjects before randomization. First, similar to our previous studies in adolescents and prepubertal subjects $(5,39)$, IGF-I is correlated to peak $\dot{\mathrm{V}}_{2}$, most likely reflecting the strong relationship between muscle mass and activity of the GH $\rightarrow$ IGF-I axis.

Also, similar to recent observations that we made in prepubertal girls (5), was the finding of a value of BMI percentile above which systematic changes in GHBP levels occur (Fig. 1). In frankly obese subjects, $\mathrm{GH}$ is known to be suppressed without reductions in IGF-I (40). This finding suggests a tissue alteration in response to the low levels of $\mathrm{GH}$, probably through an increase in GH receptors. GHBP, the extracellular component of the GH receptor, may reflect GH receptor numbers, but the precise relationship between the regulation of GHBP and its "parent" GH receptor is not yet fully elucidated (41). Along these lines, the inverse correlation between GHBP and peak $\dot{\mathrm{V}}_{2} / \mathrm{kg}$ found in the present study are consistent with the BMI data. Subjects with low peak $\dot{\mathrm{V}}_{2} / \mathrm{kg}$ (i.e. relatively unfit) tended to have relatively high fat stores.

In summary, we demonstrated significant, exercise-training associated increases in IL- $1 \beta$, TNF- $\alpha$, and IGFBP-2, with concomitant decreases in IGF-I and IGFBP-3. These data suggest that a 5-wk exercise intervention induced a systemic, catabolic environment in pre-pubertal and early pubertal boys. These findings are surprising considering the documented increase in fitness (i.e. peak $\dot{\mathrm{V}}_{2}$ ). Whether or not this catabolic environment abates as exercise training progresses and, eventually, there is a rebound in the activity of the GH $\rightarrow$ IGF-I axis (reflected in increased levels of circulating IGF-I) is not yet known. Finally, the data lead to the speculation that levels of physical activity might influence growth by altering both catabolic and anabolic mediators.

\section{REFERENCES}

1. LeRoith D 1991 Insulin-Like Growth Factors: Molecular and Cellular Aspects. CRC Press, Boca Raton, FL

2. Kelly PJ, Eisman JA, Stuart MC, Pocock NA, Sambrook PN, Gwinn TH 1990 Somatomedin-C, physical fitness, and bone density. J Clin Endocrinol Metab 70:718-723

3. Poehlman ET, Copeland KC 1990 Influence of physical activity on insulin-like growth factor-I in healthy younger and older men. J Clin Endocrinol Metab 71:1468-1473

4. Eliakim A, Brasel JA, Barstow TJ, Mohan S, Cooper DM 1998 Peak oxygen uptake, muscle volume, and the growth hormone-insulin-like growth factor-I axis in adolescent males. Med Sci Sports Exerc 30:512-517

5. Eliakim A, Scheett TP, Newcomb R, Mohan S, Cooper DM 2001 Fitness, training, and the growth hormone->insulin-like growth factor I axis in prepubertal girls. J Clin Endocrinol Metab 86: 2797-2802
6. Eliakim A, Brasel JA, Mohan S, Cooper DM 1998 Increased physical activity and the growth hormone insulin-like growth factor-I axis in adolescent males. Am J Physiol 275:R308-R314

7. Eliakim A, Brasel JA, Mohan S, Barstow TJ, Berman N, Cooper DM 1996 Physical fitness, endurance training, and the GH-IGF-I system in adolescent females. J Clin Endocrinol Metab 81:3986-3992

8. Pedersen BK, Hoffman-Goetz L 2000 Exercise and the immune system: regulation, integration, and adaptation. Physiol Rev 80:1055-1081

9. Scheett TP, Milles PJ, Ziegler MG, Stoppani J, Cooper DM 1999 Effect of exercise on cytokines and growth mediators in prepubertal children. Pediatr Res 46:429-434

10. Lohman TG 1992 Advances in Body Composition Measurement. Human Kinetics, Champaign, IL, pp 1-150

11. Beaver WL, Lamarra N, Wasserman K 1981 Breath-by-breath measurement of true alveolar gas exchange. J Appl Physiol 51:1662-1675

12. Cooper DM, Weiler-Ravell D, Whipp BJ, Wasserman K 1984 Aerobic parameters of exercise as a function of body size during growth in children. J Appl Physiol 56:628-634

13. Daughaday WH, Kapadia M, Mariz I 1987 Serum somatomedin binding proteins: physiologic significance and interference in radioligand assay. J Lab Clin Med 109:355363

14. Carlsson LMS, Rowland AM, Clark RG, Gesundheit N, Wong WLT 1991 Ligandmediated immunofunctional assay for quantitation of growth hormone-binding protein in human blood. J Clin Endocrinol Metab 73:1216-1223

15. Eliakim A, Barstow TJ, Brasel JA, Ajie H, Lee W-NP, Renslo R, Berman N, Cooper DM 1996 The effect of exercise training on energy expenditure, muscle volume, and maximal oxygen uptake in adolescent females. J Pediatr 129:537-543

16. Rajaram S, Baylink DJ, Mohan S 1997 Insulin-like growth factor binding proteins in serum and other biological fluids: regulation and functions. Endocr Rev 18:801-831

17. Cappon J, Brasel JA, Mohan S, Cooper DM 1994 Effect of brief exercise on circulating insulin-like growth factor-I. J Appl Physiol 76:1418-1422

18. Scheett TP, Mills PJ, Ziegler MG, Stoppani J, Cooper DM 1999 Effect of exercise on cytokines and growth mediators in prepubertal children. Pediatr Res 46:429-434

19. Nindl BC, Kraemer WJ, Marx JO, Arciero PJ, Dohi K, Kellogg MD, Loomis GA 2001 Overnight responses of the circulating IGF-I system after acute, heavyresistance exercise. J Appl Physiol 90:1319-1326

20. Clemmons DR 1992 IGF binding proteins: regulation of cellular actions. Growth Regul 2:80-87

21. Walker BR, Best R, Noon JP, Watt GC, Webb DJ 1997 Seasonal variation in glucocorticoid activity in healthy men. J Clin Endocrinol Metab 82:4015-4019

22. Smith AT, Clemmons DR, Underwood LE, Ben-Ezra C, McMurray R 1987 The effect of exercise on plasma somatomedin-C/insulinlike growth factor I concentrations. Metabolism 36:533-537

23. Koziris LP, Hickson RC, Chatterton Jr RT, Groseth RT, Christie JM, Goldflies DG, Unterman TG 1999 Serum levels of total and free IGF-I and IGFBP-3 are increased and maintained in long-term training. J Appl Physiol 86:1436-1442

24. Gulmans V, van der LJ, Wattimena D, van Doom J, Oostveen D, Berger R, de Meer K 2001 Insulin-like growth factors and leucine kinetics during exercise training in children with cystic fibrosis. J Pediatr Gastroenterol Nutr 32:76-81

25. Roemmich JN, Sinning WE 1997 Weight loss and wrestling training: effects on growth-related hormones. J Appl Physiol 82:1760-1764

26. Jahreis G, Hesse V, Schmidt HE, Scheibe J 1989 Effect of endurance exercise on somatomedin-C/insulin-like growth factor I concentration in male and female runners. Exp Clin Endocrinol 94:89-96

27. Ostrowski K, Hermann C, Bangash A, Schjerling P, Nielsen JN, Pedersen BK 1998 A trauma-like elevation of plasma cytokines in humans in response to treadmill running. J Physiol. 513:889-894

28. Rohde T, MacLean DA, Richter EA, Kiens B, Pedersen BK 1997 Prolonged submaximal eccentric exercise is associated with increased levels of plasma IL-6. Am J Physiol 273:E85-E91

29. Cimaz R, Rusconi R, Cesana B, Buoncompagni A, Corona F, Gattinara M, Gerloni V, Picco P, Bardare M 1997 A multicenter study on insulin-like growth factor-I serum levels in children with chronic inflammatory diseases. Clin Exp Rheumatol 15:691696

30. Davies UM, Jones J, Reeve J, Camacho-Hubner C, Charlett A, Ansell BM, Preece MA, Woo PM 1997 Juvenile rheumatoid arthritis. Effects of disease activity and recombinant human growth hormone on insulin-like growth factor 1, insulin-like growth factor binding proteins 1 and 3, and osteocalcin. Arthritis Rheum 40:332340

31. De Benedetti F, Alonzi T, Moretta A, Lazzaro D, Costa P, Poli V, Martini A, Ciliberto G, Fattori E 1997 Interleukin 6 causes growth impairment in transgenic mice through a decrease in insulin-like growth factor-I. A model for stunted growth in children with chronic inflammation. J Clin Invest 99:643-650

32. Smith LL 2000 Cytokine hypothesis of overtraining: a physiological adaptation to excessive stress? Med Sci Sports Exerc 32:317-331

33. Krakauer T, Vilcek J, Oppenheim JJ 1999 Proinflammatory cytokines. In: Paul WE (ed) Fundamental Immunology, 4th Ed. Lippincott-Raven, Philadelphia, pp 775-811

34. Tisdale MJ 2001 Loss of skeletal muscle in cancer: biochemical mechanisms. Front Biosci 6:D164-D174

35. Schwarz AJ, Brasel JA, Hintz RL, Mohan S, Cooper DM 1996 Acute effect of brief low- and high-intensity exercise on circulating IGF-I, II, and IGF binding protein-3 and its proteolysis in young healthy men. J Clin Endocrinol Metab $81: 3492-3497$

36. Ristimaki A, Narko K, Enholm B, Joukov V, Alitalo K 1998 Proinflammatory cytokines regulate expression of the lymphatic endothelial mitogen vascular endothelial growth factor-C. J Biol Chem 273:8413-8418

37. Reardon KA, Davis J, Kapsa RM, Choong P, Byrne E 2001 Myostatin, insulin-like 
growth factor-1, and leukemia inhibitory factor mRNAs are upregulated in chronic human disuse muscle atrophy. Muscle Nerve 24:893-899

38. Blotnick S, Peoples GE, Freeman MR, Eberlein TJ, Klagsbrun M 1994 T lymphocytes synthesize and export heparin-binding epidermal growth factor-like growth factor and basic fibroblast growth factor, mitogens for vascular cells and fibroblasts: differential production and release by CD4+ and CD8 + T cells. Proc Natl Acad Sci U S A 91:2890-2894

39. Tirakitsoontorn P, Nussbaum E, Moser C, Hill M, Cooper DM 2001 Fitness, acute exercise, and anabolic and catabolic mediators in cystic fibrosis. Am J Respir Crit Care Med 164: 1432-1437

40. Saitoh H, Kamoda T, Nakahara S, Hirano T, Nakamura N 1998 Serum concentrations of insulin, insulin-like growth factor(IGF)-I, IGF binding protein (IGFBP)-1 and -3 and growth hormone binding protein in obese children: fasting IGFBP-1 is suppressed in normoinsulinaemic obese children. Clin Endocrinol 48:487-492

41. Baumann G 2001 Growth hormone binding protein. J Pediatr Endocrinol Metab $14: 355-375$

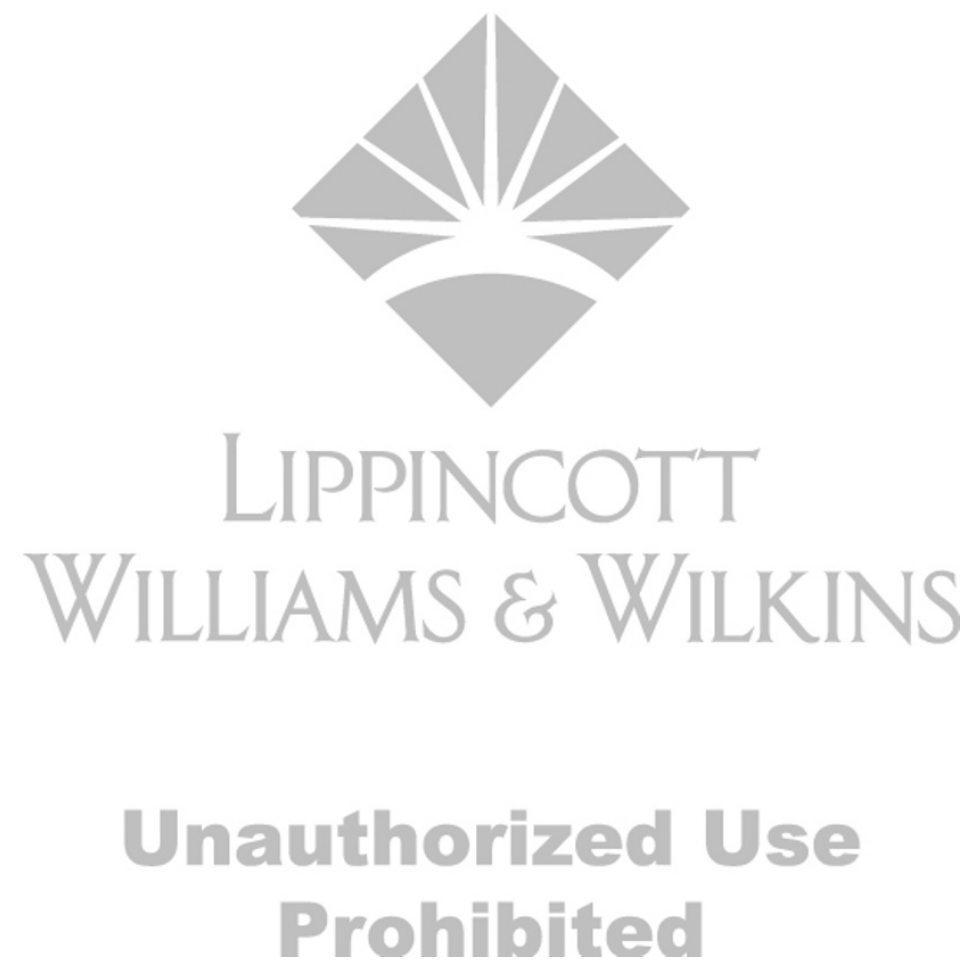

